\title{
INDONESIAN JOURNAL OF ENGINEERING RESEARCH
}

2021, Vol. 2, No. 2, $38-46$

http://dx.doi.org/10.11594/ijer.02.02.02

\section{Research Article}

\section{Development of A Solar Powered DC Drive for Rickshaw}

\author{
David O. Agbo ${ }^{*}$, Irene U. Ukazu², Gabriel A. Igwue ${ }^{3}$ \\ 1,3Department of Electrical/Electronic Engineering, Federal University of Agriculture Makurdi, \\ P.M.B. 2373, Nigeria \\ 2Department of Electrical/Electronic Engineering, Federal College of Education Panshi, Plateau, \\ Nigeria
}

Article history:

Submission November 2021

Revised November 2021

Accepted November 2021

${ }^{*}$ Corresponding author:

E-mail:

agbo.david@gmail.com

\begin{abstract}
The solar powered DC drive for a rickshaw is an automobile that uses solar energy to drive a DC motor, which in turn move a rickshaw. Due to the challenge of global warming, it has become necessary to make use of power sources that are environmentally friendly or renewable energy. Solar energy is used as the energy source in this design because it is cheap, clean and readily available during the day. This paper employed the use of solar PV which converts the solar energy into electrical energy. The electrical energy generated by the solar PV comes in the rated value of $12 \mathrm{~V}$ or $24 \mathrm{~V}$ which increases or decreases beyond this rated values depending on the sun intensity. To make use of the varying solar PV voltage, there is need to either buck (stepdown) or boost (step up) or buck-boost (stepdown-step up) the $\mathrm{PV}$ voltage to a constant voltage value. Since $12 \mathrm{~V}$ DC drive is used, it is required to step up or step down from the voltage range of $10 \mathrm{~V}$ to $25 \mathrm{~V}$ to $12 \mathrm{~V}$ via a buck-boost converter to power the $12 \mathrm{~V}$ DC drive. The DC motor control was implemented by embedding the functions of vehicle control in the system. The functions are; run, stop or break, left and right. This function makes the DC drive to control the rickshaw as vehicle. The results shows that rickshaw can be control and driven as a vehicle using solar energy.
\end{abstract}

Keywords: solar energy, buck-boost, control, microcontroller, DC motor

\section{Introduction}

Almost every mechanical movement that are made around us are accomplished by electric motors. Electric machines are a means of converting electrical energy to mechanical energy. Hundreds of devices are powered by electric motor that we use in everyday life and these motors come in various sizes. Some are of large motor applications include elevators, electric trains, hoists, and heavy metal rolling mills and while some are for small motor applications include motors used in automobiles, robots, hand power tools and food blenders.

Electric motors are broadly classified into two different categories: DC (Direct Current) and AC (Alternating Current) and within these categories are numerous types, each offering unique abilities that are suited for specific 
applications. Regardless of the type, electric motors consist of a stator (stationary field) and a rotor (the rotating field or armature) and operate through the interaction of magnetic flux and electric current to produce rotational speed and torque. DC motors are distinguished by their ability to operate from direct current. There are different kinds of DC motors, but they all work on the same principles.

A tricycle (rickshaw), often abbreviated to trike (Quellin, 2011), (Michelle et al., 2010), (Popular Science, 1980) is a human powered (or gravity-powered) three wheeled vehicle. Some tricycles, such as cycle rickshaws (for passenger transport) and freight trikes, are used for commercial purposes, especially in the developing world, particularly Africa and Asia. In this design, a prototype design of tricycle was designed using solar as source of power to reduce the consumption of other form of energy to minimal. The solar energy comes from the use of solar panels arrange in arrays to give the required current needed by the DC motor which will be used to drive the tricycle. The DCDC buck boost converter is used to either step up or step down the DC voltage of the solar panel to the nominal voltage of the DC motor used. Other features of tricycle were incorporated into the design; features such as: stop, run, forward, reverse and speed control of the DC motor.

\section{Review of Past Journals}

In (Arunsankar \& Ranjithkumar, 2015), the performance analysis of DC series motor using buck boost converter was researched. The characteristics for step up and step down of the output voltage of the buck boost converter are studied and it was found that this system possesses a good operation performance with a minimum ripple in the output of the motor current and voltage.

The proposal of (Hussein, 2015) for the research on hybrid fuzzy-PID controller for buckboost converter in solar energy-battery systems which a PID, a Fuzzy logic controller, and hybrid fuzzy PID control system was designed and simulated to stabilize the output voltage of the buck-boost converter. The performance results using dynamic response of all of these controllers in terms of rise time, overshoot, peak time, and voltage oscillation shows that simulation results support the validity and advantages of the hybrid method.

Design and simulation of DC-DC converters was researched by (Lopa et al., 2016). This research paper focuses especially the design and simulation of DC-DC converters. Simulation results for buck, boost and buck-boost converters were shown with the chance of different input parameters.

In (Baharudin et al., 2017), the researched on Topologies of DC-DC converter in solar PV applications with various circuit topologies of DC-DC converters in solar photovoltaic (PV) applications were presented and they are buck, boost and buck-boost converter in various applications.

The research of (Viswanatha \& Venkata, 2017), on microcontroller based bidirectional buck-boost converter for PV power plant in which the controller was designed to take care of mode transition, from buck to boost and boost to buck mode automatically based on source voltage.

\section{Methods}

Figure 1 shows the block diagram of solar powered rickshaw using single phase DC motor. The solar PV generates the voltage and current and this solar voltage is either step up or step down by the buck-boost converter. The output from the buck-boost converter is used to drive the DC motor. The Start/Stop switch is to run or stop the DC motor movement, while forward (Fwd)/reverse (Rev) switch controls the direction of rotation of the DC motor either in clockwise $(\mathrm{Cw})$ or anticlockwise (Acw) and the variable switch controls the speed of the DC motor. The LCD is used to display state of the solar voltage, motor speed and other information. Table 1 shows the characteristic of the proposed rickshaw parameters while Table 2 show the characteristic of the DC motor that is used to achieve Table 1. 


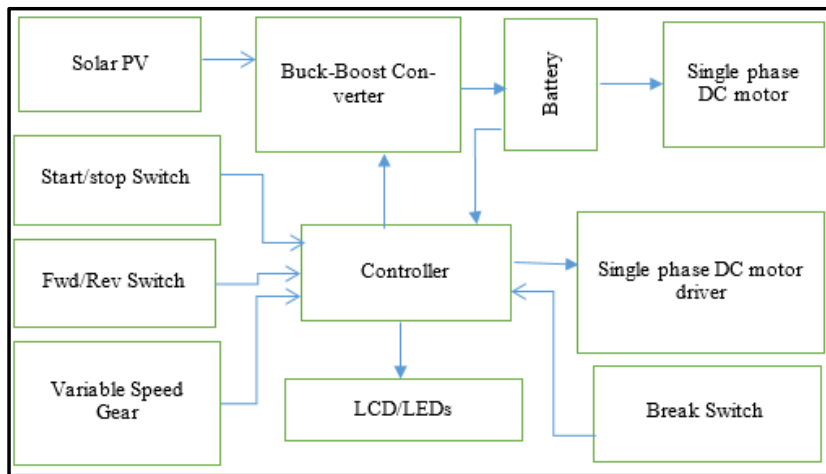

Figure 1. Block Diagram of Solar Powered rickshaw using Single Phase DC Motor
Table 1. Specification of the Proposed SolarPowered Rickshaw

\begin{tabular}{ll}
\hline Parameters & Ratings \\
\hline Idle Speed(RPM) & $1500 \mathrm{RPM}$ \\
Brake(Front/Rear) & Electrical \\
Design Max Speed & $60 \mathrm{~km} / \mathrm{h}$ \\
Net Weight $(\mathrm{kg})$ & $300 \mathrm{~kg}$ \\
Maximum Load $(\mathrm{kg})$ & $400 \mathrm{~kg}$ \\
\hline
\end{tabular}

Table 2: Electric Rickshaw Motor Specifications

\begin{tabular}{cccccc}
\hline Ratings & \multicolumn{5}{c}{ DC Motor (Watts) } \\
\hline RP (W) & RV (VDC) & RS (RPM) & NLS (RPM) & RT (N.M) & RC(A)/NLC(A) \\
\hline 120 & 12 & 275 & 310 & 12.1 & $\leq 10.5 / 7 / \leq 2.5 / 2$ \\
\hline
\end{tabular}

Legend: $R R=$ rated power, $R V=$ rated voltage, $R S=$ rated speed, $N L S=$ no load speed, $R T=$ rated torque, $R C / N L C$ = rated current/no load current

\section{Design of Solar PV}

In this research, $100 \mathrm{~W}, 12 V_{d c}, 5.37 \mathrm{~A}$ Global Solar Energy FG-2BTN-100 mono-crystalline solar PV panel was arranged in array of 2 panels in parallel to generate the voltage/current output of $12 \mathrm{~V}_{\mathrm{dc}}, 10 \mathrm{~A}$.

\section{Design of the Boost Converter}

The buck-boost circuit in Figure 2 was designed based on the following considerations: Needed output voltage $=12 \mathrm{~V}$

Needed maximum load current $=10 \mathrm{~A}$

Required to maintain the output voltage at 12 $\mathrm{V} \pm 5$

Expected DC input voltage from solar PV ranges from 10 to $24 \mathrm{~V}_{\mathrm{dc}}$

All components were chosen to meet these conditions as much as is practically possible.

For bulk conversion the input voltage considered ranges from $12.1 \mathrm{~V}_{\mathrm{dc}}$ to $24 \mathrm{~V}_{\mathrm{dc}}$ and output voltage is $12 \mathrm{~V}_{\mathrm{dc}}$, while for boost conversion the input voltage considered ranges from 11.9 $V_{\mathrm{dc}}$ to $10 \mathrm{~V}_{\mathrm{dc}}$ and the same output of $12 \mathrm{~V}_{\mathrm{dc}}$.
To obtain the values of inductor and capacitor connected across the transistor of the buck section of the buck/boost converter, equation (1), (2) and (3) were used;

$D=\frac{V_{o}}{V_{\text {in }}}$ and $R=\frac{V_{o}}{I_{o}}$

For continous current $L>\frac{(1-\mathrm{D}) \mathrm{R}}{2 \mathrm{f}}$

Therefor $\mathrm{C}>\frac{(1-\mathrm{D})}{8 \mathrm{~L}\left(\Delta \mathrm{V}_{\mathrm{o}} / \mathrm{V}_{\mathrm{o}}\right) \mathrm{f}^{2}}$

To obtain the values of inductor and capacitor connected across the transistor of the boost of the buck-boost converter equations (4), (5) and (6) were used.

$\mathrm{D}=1-\frac{\mathrm{V}_{\text {smax }}}{\mathrm{V}_{\mathrm{o}}}$

For continous current $L>\frac{D(1-D)^{2} R}{2 f}$

Therefor $C>\frac{D}{R\left(\Delta V_{o} / V_{o}\right) f}$ 




Figure 2. Non-Inverting Buck-Boost Converter Circuit

The Operation of the Solar Powered Rickshaw

The circuit diagram of the solar powered DC motor rickshaw is shown in Figure 3 and is divided into two sections; the power section and the control section. The power section comprises of the solar PV and the buck-boost converter circuit. The solar PV generates the power energy that ranges from $10 \mathrm{~V}$ to $24 \mathrm{~V}$ of $10 \mathrm{~A}$, which serves as the input power to the buck-boost converter. The buck-boost converter steps down or steps up to a constant output voltage of $12 \mathrm{~V}$ of $5 \mathrm{~A}$, that is used to power the DC motor (EG1108_DC motors, 2005). The control circuit has five inputs, the solar voltage/current input, stop and run input, forward (fwd) and reverse (rev) input, and the variable speed control input. The solar voltage is used as input to the PIC18f4550 microntroller (PIC18F4550 datasheet, 2004), the pic18f4550 uses this input voltage to control the switching of the buck-boost circuit to ensure constant 12 $\mathrm{V}$ at the output of the buck-boost. The stop switch puts the system in idle state while the run switch puts the system in active state. The fwd or rev switch controls the direction of the DC motor to move either in clockwise (cw) or anticlockwise (acw) direction and lastly the variable switch controls the speed of the DC motor. There are four led at the output that displays the state of the DC motor and the LCD displays the solar PV voltage and the state of the DC motor. The Mosfet drivers IR2111 (IR2111 Datasheet, 2004) were connected to the microcontroller to step up the microcontroller voltage to enable it to drive the Mosfets IRF640 (IRF460 Datasheet, 2014) and the microcontroller controls all other peripherals.

Figure 4 shows the buck-boost converter flowchart begins with the start and then initializes and obtain the solar PV voltage (SPV). The SPV is compared with $12 \mathrm{~V}$ if the SPV is greater than $12 \mathrm{~V}$, the system bucks the SPV to $12 \mathrm{~V}$, if the SPV is less than $12 \mathrm{~V}$ but greater than $10 \mathrm{~V}$, the system boosts the SPV to $12 \mathrm{~V}$. But if the SPV is less than $10 \mathrm{~V}$ the buck-boost converter turns off.

Figure 5 shows the DC motor control flowchart starts by initializing the switches that controls the motor. If the run switch is pressed it checks if it's in fwd or rev state. If it's in fwd state, the motor moves in cw direction if in rev state the motor moves in acw direction and the speed of the motor is automatically set to idle speed mode. The speed of the motor is always updated depending on the value of the variable resistor. But if the stop switch is pressed the DC motor control system will be in idle state. 
Matlab was used to determining the parameter and responses of the buck-boost converter before simulating the buck boost converter in protues. The simulation of electronic circuits of the solar powered DC motor rickshaw especially the microcontroller section was simulated in Proteus 8 professional IDE (Proteus PCB Design \& Simulation Software - Labcenter
Electronics, 2017), by burning the C program written in MikroC IDE (MikroElektronika, 2013) which converts the c code to hex code. Implementation of the hardware circuit was achieved by burning the hex file into the microcontroller using picKit 2 programmer (PICkit 2 Development Programmer and Debugger pg164120, 2017).



Figure 3: Circuit Diagram of the Solar Powered Rickshaw

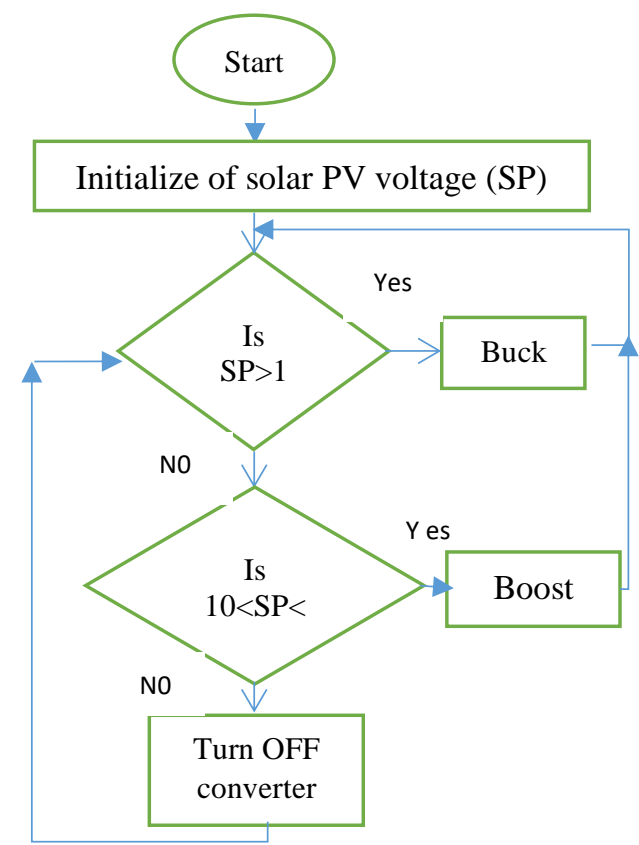

Figure 4. Solar PV, buck-boost 


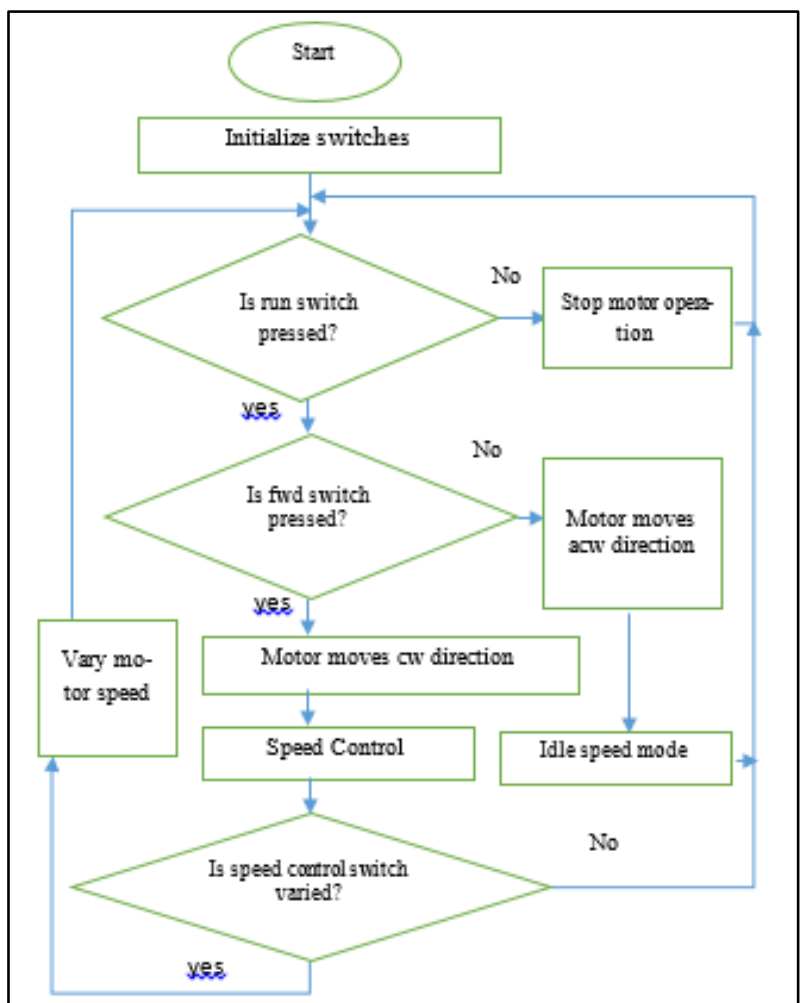

Figure 5. Flowchart of DC Motor Control

\section{Results and Discussion}

Figure 6 shows the result of the Matlab simulation obtained from Figure 2. Figures 7 and 8 show the results on the buck-boost converter when the solar PV voltage varies.
Figures 9 to 11 shows the actions taken when the stop, run, fwd and rev buttons were pressed and the control of the rickshaw speed by the variable resistor, while Figure 12 shows the implementation of the complete system.

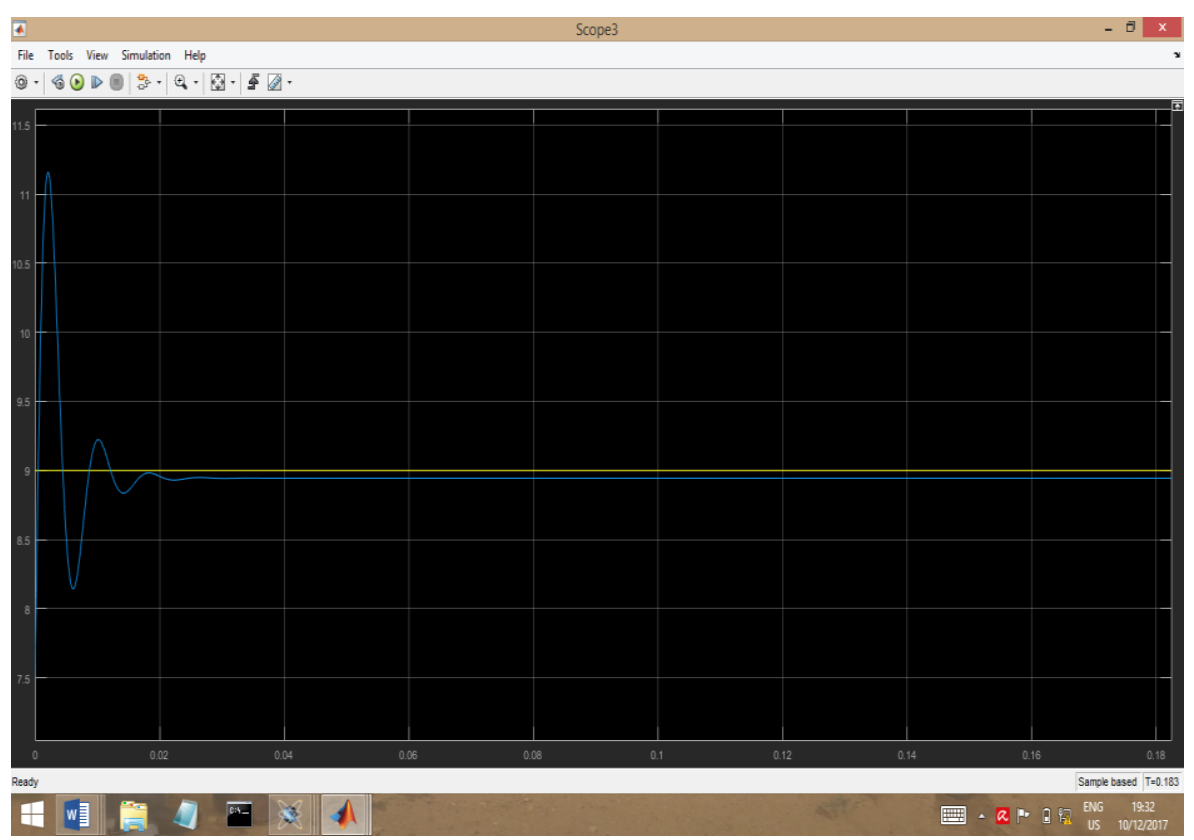

Figure 6. The output waveform of MATLAB simulation of non-inverting buck-boost converter 


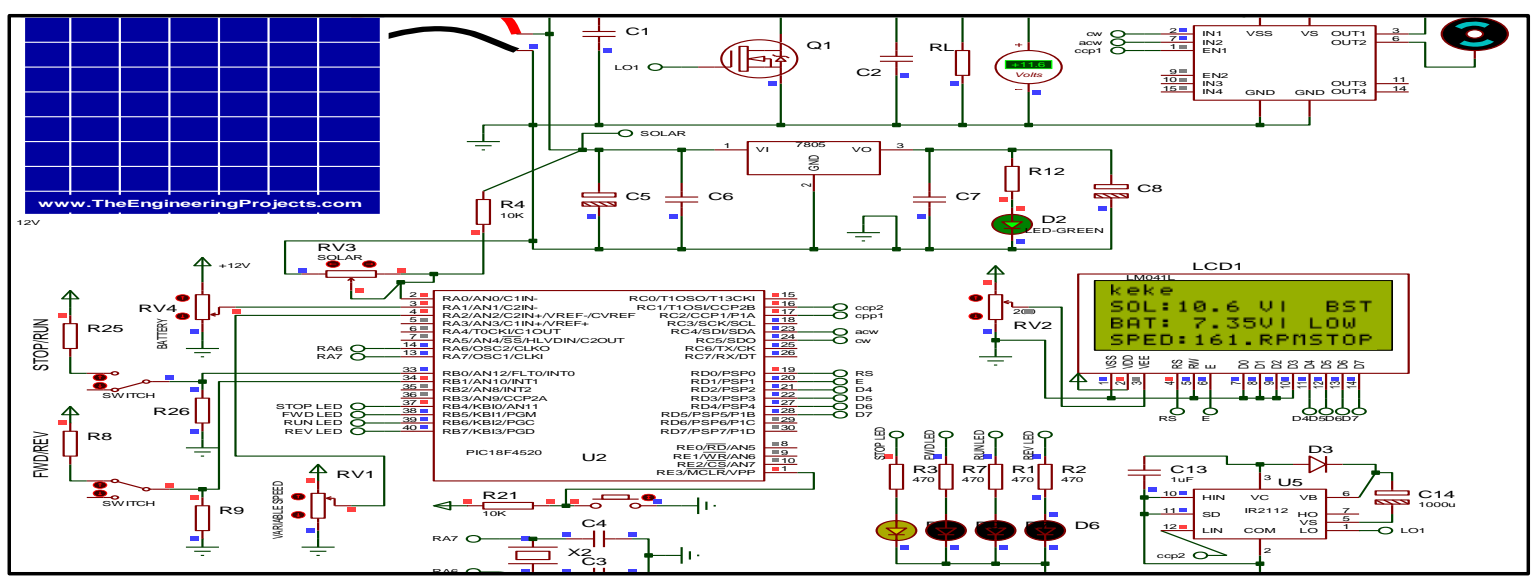

Figure 7. Battery Low and Solar PV is below $12 \mathrm{~V}$

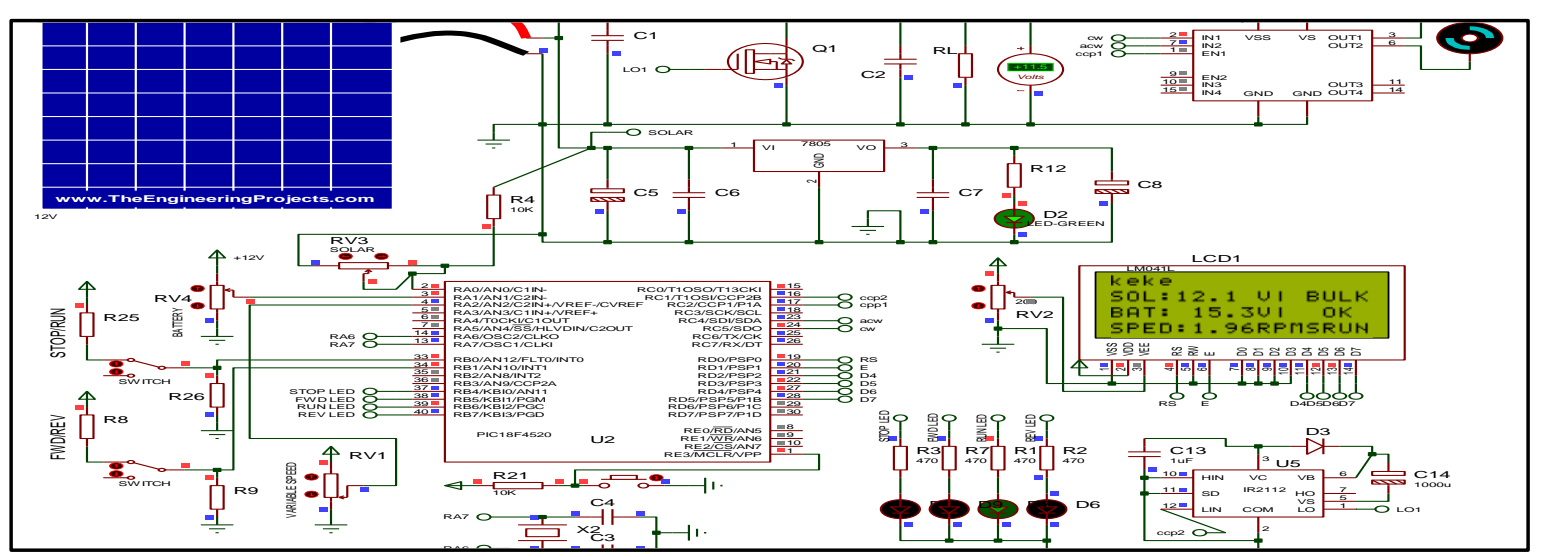

Figure 8. Solar Voltage greater than $12 \mathrm{~V}$

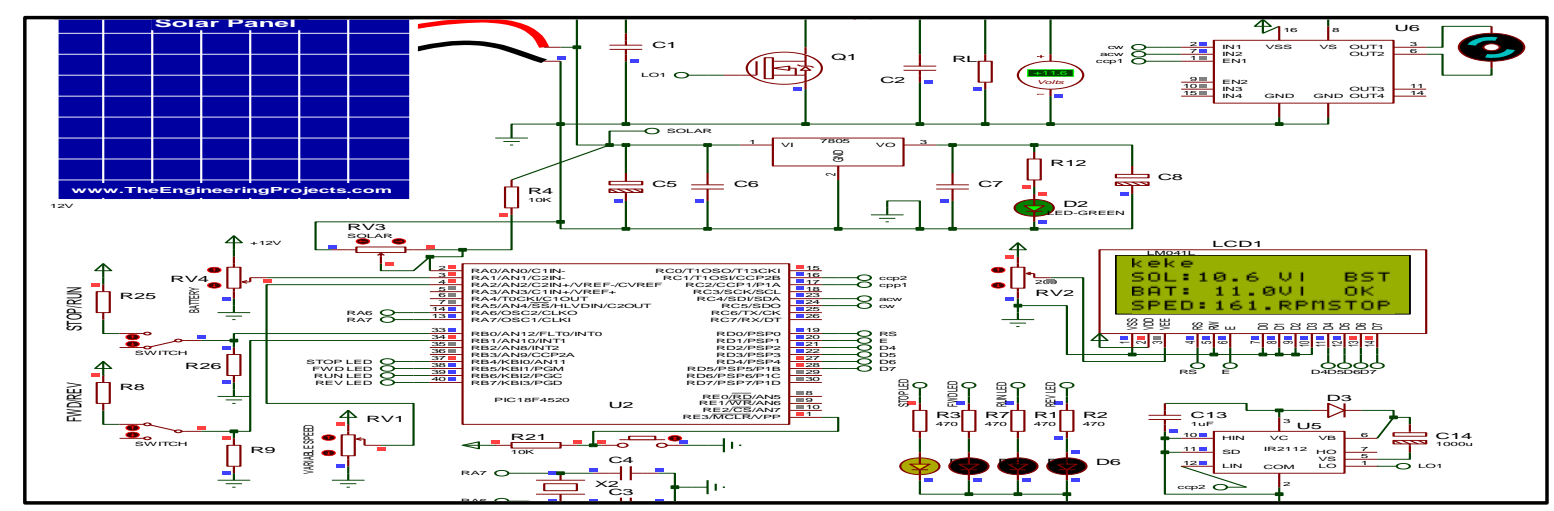

Figure 9. When Stop Button is Selected 




Figure 10. When Run and Forward Buttons are selected

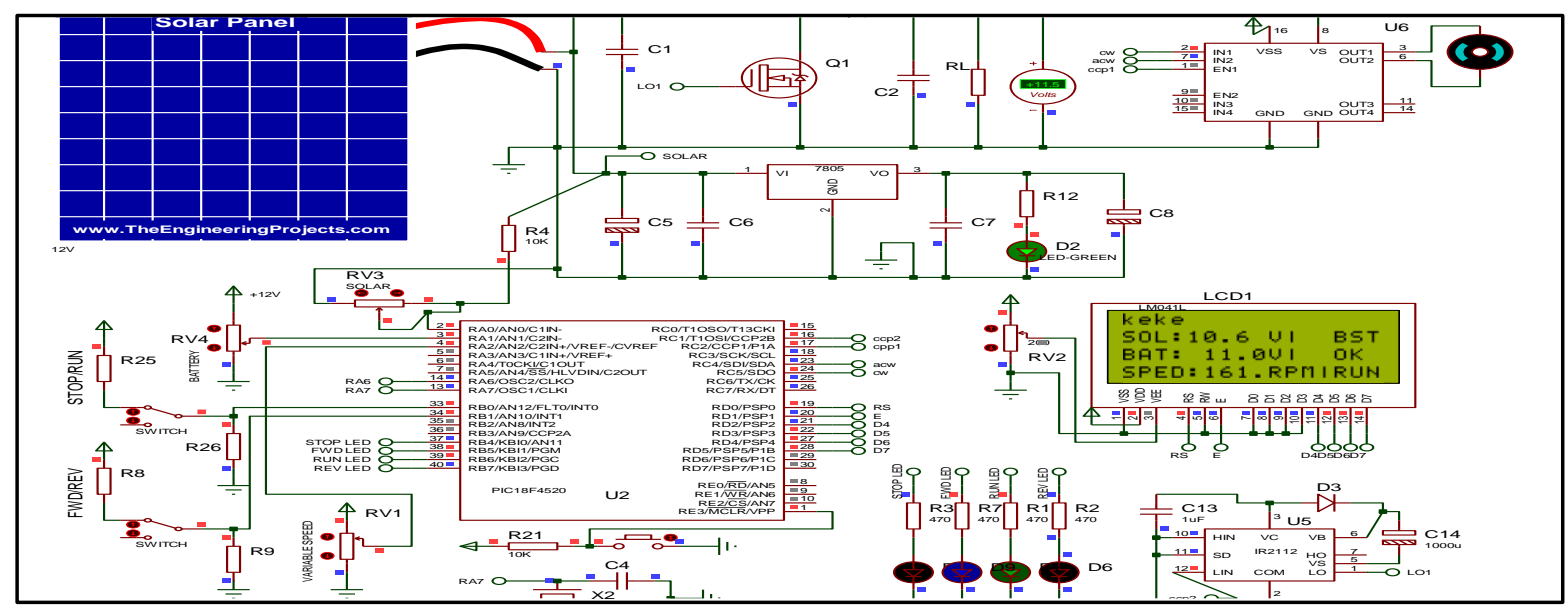

Figure 11. When Run and Rev Button are selected

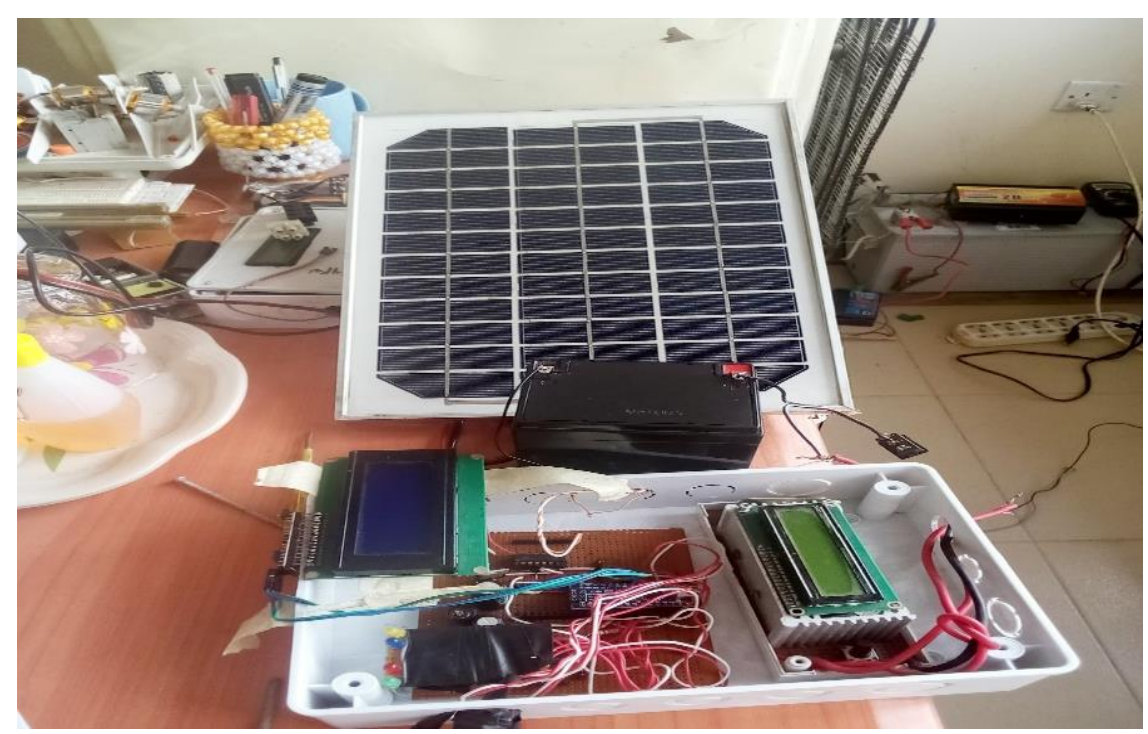

Figure 12. Hardware Implementation

The Matlab simulation is used to get the parameters of buck and boost voltage with less distortion or variation from the set output voltage.
Figure 7 shows when the battery is low and the solar voltage is below $12 \mathrm{~V}$ but above $10 \mathrm{~V}$, the solar charge the battery by stepping up (boost) the voltage from below $12 \mathrm{~V}$ to $12 \mathrm{~V}$. If 
the solar PV voltage is below $10 \mathrm{~V}$, there will no charging. Figure 8 when the solar PV voltage is above $12 \mathrm{~V}$, stepping down (buck) occurs to step down the voltage to $12 \mathrm{~V}$. Figure 9 shows when the stop button of the system is pressed. The system comes a rest, only the charging unit will be active. Figure 10 shows when the run and forward buttons are selected, the speed of the motor comes active for the driver to increase or decrease the speed of the motor. Figure 11 shows when the run and reverse buttons are selected, the speed of the motor automatically goes to idle speed mode to enable the driver drives the motor in reverse direction. If the battery of the system is below $10 \mathrm{~V}$, the system automatically go to sleep mode, that is becomes in-active. Figure 12 shows the hardware implementation.

\section{Conclusions}

The implementation was achieved using a 12 V, 5 A DC motor with Two (2) 100W solar panels. This design will help to reduce the emission of gas by fuel rickshaw which in turn reduce global warming.

\section{References}

Adam Quellin (2011). The Little Book of Trikes. Veloce Publishing Ltd.

Arunsankar G. and R.Ranjithkumar (2015). Performance Analysis of Dc Series Motor Using Buck Boost Converter, International Journal of Latest Research in Science and Technology, 4(2): 118-121.

EG1108_DC motors, (2005).
IR2111 Datasheet (2004). International IOR Rectifier, 233 Kansas St. El, Segundo, California.

IRF460 Datasheet (2014), International IOR Rectifier, 233 Kansas St. El, Segundo, California.

Karime Farhood Hussein (2015). Hybrid Fuzzy-PID Controller for Buck-Boost Converter in Solar Energy-Battery Systems, Department of Electrical and Computer Engineering, Western Michigan University.

Katherine Cuthbert (2010). Keeping Balance: A Psychologist's Experience of Chronic Illness and Disability. Troubador Publishing Ltd.

Michelle et al. (2010). The Hanukkah Trike, Albert Whiteman Company, 1 Sept. 2010

MikroElektronika, MikroC, 2013. Available from: http://mikroe.com/

Nor Hanisah Baharudin, Tunku Muhammad Nizar Tunku Mansur, Fairuz Abdul Hamid, Rosnazri Ali, Muhammad Irwanto Misrun (2017). Topologies of DC-DC Converter in Solar PV Applications, Indonesian Journal of Electrical Engineering and Computer Science 8(2): pp. 368-374.

"PICkit 2 Development Programmer and Debugger pg164120 | Microchip Technology Inc.", Microchip.com, 2017. [Online]. Available: http://www.microchip.com/DevelopmentTools/ProductDetails.aspx?PartNO=pg164120. [Accessed: 05- May2017].

PIC18F4550 datasheet (2004). Microchip Technology Inc. 2355t Chandler Blvd., Chandler, Arizona.

"Proteus PCB Design \& Simulation software - Labcenter Electronics", Labcenter.com, 2017. Available: https://www.labcenter.com/

Popular Science (1980), Tilting Trike Jul. 1980

Shafinaz A. Lopa, S. Hossain, M. K. Hasan, T. K. Chakraborty (2016). Design and Simulation of DC-DC Converters: International Research Journal of Engineering and Technology 3(1): pp. 63.

Viswanatha V. A., Venkata Siva Reddy R (2017). Microcontroller Based Bidirectional Buck-Boost Converter for Photo-Voltaic Power plant. Journal of Electrical Systems and Information Technology. 